Conferência 


\section{LÍNGUA E LITERATURA: UMA FALSA DICOTOMIA}

Beth Brait ${ }^{\circ}$

omeço minha exposiçāo com palavras do grande poeta
português Fernando Pessoa que escolhi porque parecem sintetizar e possibilitar uma reflexão sobre o tema desta IV Semana de Letras da Universidade Mackenzie: Lingua e Literatura: uma falsa dicotomia. Fernando Pessoa diz: Quem não vé bem uma palaura nāo pode ver bem uma alma, explicitando a relaçāo constitutiva existente não apenas entre linguagem e vida, mas também entre lingua e literatura.

E eu tomo esta frase-verso na medida em que ela possibilita pensar palavra como metonímia de lingua, ou seja, uma entidadeidentidade de um povo, de um tempo-espaço, de uma maneira particular de relacionamento do homem com o mundo e com os outros homens que, aqui, o poeta convida a ser vista, a ser observada com o mesmo cuidado, com a mesma proximidade, com o mesmo fino trato necessário ao observador que deseja visualizar uma alma.

Evidentemente que por alma podemos entender tanto a profundidade que está por trás da materialidade observável nas expressōes individuais, quanto a ideologia, os valores, o diálogo polêmico ou conciliatório que existe entre os muitos discursos que um discurso, um texto, uma expressão, ou mesmo uma única palavra carregam como condição constitutiva de existência. A diversidade com que esta pala-

- LAEL-PUC-SP/FFLCH-USP/CNPq. 
BRAIT, Beth. Lingua e literatura: uma falsa dicotomia.

vra - alma - pode ser apreendida é a prova de que sob a materialidade dos sons ou das letras agita-se um mar de significados, de significações, de sentidos que somente uma interação especifica, particular, circunscrita a tempo, espaço e interlocutores poderá tentar represar, capturar, explorar enquanto memória e vida.

E mais. Essa afirmação de Fernando Pessoa, por essa leitura que começo a fazer, evidentemente me surgiu, atravessou meus pensamentos, enquanto eu refletia sobre esta minha exposição. Ela pareceu, e justamente parece neste momento, ter sido dita pelo poeta a propósito do tema que rege esta IV Semana de Letras e, especialmente, a respeito do fazer especifico daqueles que escolheram a carreira de Letras como profissão e que estão treinando, aguçando olhos e ouvidos para uma escuta e para uma visão muito especial em relaçāo às palavras, às diferentes maneiras como elas podem ser articuladas, com outras palavras ou com outros signos de natureza não verbal, para produzir sentidos, mostrando-se através dos mais variados gêneros, tão variados quanto são as atividades humanas.

Assim sendo, tanto a literatura, essa forma privilegiada de expressāo, representação, conhecimento e invenção do homem e do mundo, como todas as outras formas, consideradas, num certo sentido, menos nobres, como é o caso da fala cotidiana, da midia e até mesmo das interações internéticas, internáuticas, tão em voga neste momento, passam necessariamente pela lingua e, conseqüentemente, mobilizam e revelam as múltiplas faces desse instrumento que, dependendo do suporte, das condiçōes de produçāo, das formas de circulação e recepção, reflete e refrata as maneiras de ser, de ver e de enfrentar o mundo de uma dada comunidade em um dado momento histórico, social, cultural.

O profissional de Letras, hoje, que tem na linguagem seu instrumento, seu objeto, sua matéria-prima, terá necessariamente de estar apto, enquanto escuta e enquanto olhar, para essa multiplicidade de formas de mobilização da língua, impedido, pela própria natureza do objeto que caracteriza o seu fazer, de assumir uma possivel 
dicotomia entre lingua e literatura, uso e criatividade, especialmente no que diz respeito ao ensino e à pesquisa.

A literatura é uma das possibilidades de exploração e utilização da lingua, das palavras, para uma diversidade de fins, de propósitos os quais as teorias literárias e as teorias lingüisticas, bem como outras vertentes dos estudos das linguas e das literaturas, têm contribuido decisivamente para caracterizar, pontuando as mudanças de acordo com os diferentes momentos históricos, com os diferentes povos, com as diferentes linguas, mas sempre, apesar de todas as diferenças de gêneros e conteúdos, apontando para essa marca da natureza humana que é o fazer literário, o fazer poético, fazer em que a lingua, em sua modalidade escrita ou oral, é utilizada para expressar e justificar a existência humana.

Segundo o escritor irlandês Oscar Wilde, A literatura antecipa sempre a vida. Ela não a copia em nada, mas a molda segundo seus fins. Essa afirmaçāo poderia ser completada com as palavras do filósofo Hiedegger que especifica a intrínseca relação existente entre língua e literatura: A lingua é o poema original por meio do qual um povo dizo ser. Inversamente, a grande poesia, aquela pela qual um povo entra na história, é aquilo que começa a dar figura à sua lingua.

$\hat{E}$, inicialmente, nesse sentido, que a dicotomia lingua e literatura, apontada como falsa na temática que rege esta IV Semana de Letras, pode ser pensada. Quem aprende com a literatura, quem trabalha com a literatura, quem ensina literatura e quem desfruta o prazer e o conhecimento que ela pode trazer, naturalmente está constitutivamente ligado à lingua. Como separar as duas coisas em Guimarães Rosa, em Camões, em Clarice Lispector, para ficarmos somente em três dos inúmeros manejadores de linguas, que as fazem aparecer de novo, como novas e nunca utilizadas como tal? Como estudar lingua sem buscar nos inúmeros gêneros aquele que parece apropriar-se de todos os demais?

Mas esse caminho nāo é o único para pensarmos essa falaciosa dicotomia. Ela foi tomada como tema, imagino, porque teima em rea- 
BRAIT, Beth. Lingua e literatura: uma falsa dicotomia.

parecer, sob diferentes máscaras, como uma realidade dos cursos de Letras, aparentemente refletida e consignada na escolha que as pessoas fazem, voltando-se mais para o estudo da Lingua que para o da Literatura e vice-versa. Estamos vivendo um momento em que a fragilidade dessa separação é uma evidência, quer nos cursos de Letras, quer nos caminhos profissionais para os quais esses cursos preparam.

Para podermos observar mais de perto essa evidência, ou seja, para avaliarmos o quanto o profissional de Letras necessita despertar sua sensibilidade e aguçar suas possibilidades de ver, analisar e enfrentar o mundo a partir de sólidos e articulados conhecimentos de lingua e literatura, situando-se sob uma perspectiva contemporânea, condizente com as teorias e a realidade atual, é necessário levarmos em conta uma certa historicidade da relaçāo existente entre esses dois ramos do conhecimento que, ao mesmo tempo, são formas de expressão da individualidade e da coletividade.

Essa relação está situada, historicamente, dentro da tradição do que se estabelece, a cada época, ser um curso de Letras, consideradas as disciplinas que deverão estar ai implicadas, as formas de ensino e o conteúdo dessas disciplinas e, evidentemente, o tipo de formaçāo e o tipo de profissional, se for o caso, que deverá resultar dessa combinatória. É, portanto, um conceito de linguagem, sua dimensão e seu alcance social que definem o perfil do ensino das Letras. Para esboçar de forma mais prática o que estou tentando dizer, vou escolher dois caminhos: o primeiro, a recuperaçāo rápida e resumida da forma como essa relaçāo está refletida nos curriculos do século do XIX e parte do $\mathrm{XX}$; e o segundo, a análise de textos, em sua dimensão verbo-visual, a partir de categorias advindas do conceito de linguagem que hoje rege os cursos de Letras e que possibilita um trânsito bastante forte entre os ensinamentos lingüisticos e literários, bem como entre textos literários e não literários, verbais e não verbais. $O$ objetivo, nos dois casos, será recuperar alguns aspectos que demonstram diferentes maneiras de conceber a relaçāo lingua/literatura de um 
ponto de vista pedagógico, acadêmico e, necessariamente, cultural e histórico.

Se voltarmos nosso olhar para o século XIX, poderemos observar, como afirma Roberto Acizelo de Souza em sua obra $O$ império da eloqüència', que "Durante o século XIX, há no Brasil, ao longo de um periodo que coincide quase integralmente com o ciclo do Império, um grande interesse pelos estudos da retórica (a que se anexavam ou com que se confundem os de poétical, interesse traduzido por várias publicaçōes e pela inserção das disciplinas mencionadas nos curriculos escolares. Observa-se, contudo, que esse interesse desaparece no final dos anos 1800, embora diversos residuos dessa tradição se tenham conservado no século XX (Souza, 1999: 39). Para demonstrar essa afirmação, o autor vai apresentar um estudo sobre "a retórica e a poética como empreendimentos disciplinares dos discursos", "um panorama dos estudos literários no Brasil", "uma análise da produção oitocentista de manuais de retórica-poética, sublinhando o compromisso reciproco entre esses manuais e o sistema de ensino e, por fim, "a questāo da influência da formaçāo retórica sobre a produção literária e atẻ sobre as condutas culturais em geral no Brasil oitocentista" (Souza, 1999: 3).

Nesse importante estudo, do qual eu lanço mão para pontuar maneiras como a relação lingua/literatura pode ser concebida, há dois aspectos que nos interessam muito de perto. O primeiro deles diz respeito ao momento em que os estudos literários se consolidaram no Brasil e às posiçōes históricas assumidas pela área de Letras no sistema de ensino brasileiro: "tendo ocupado durante o periodo colonial e o século XIX posição de grande destaque no ensino básico, praticamente constituindo sozinha esse nivel de educaçāo, apenas na década de 30 deste século seria admitida como área de profissionalização de nivel universitário, com a implantação das Faculdades de Filosofia,

1 SOUZA. Roberto Acizelo. O império da eloqüência. Rio, Editora da UERJ, 1999. Esta obra está resenhada por José Luis Jobim neste número 8 da Revista da ANPOLL. 
BRATT, Beth. Língua e literatura: uma falsa dicotomia.

Ciências e Letras" (Souza, 1999: 29). Essa observação é importante na medida em que podemos dimensionar, ainda que grosso modo pois nāo cabe aqui detalhar cada momento como faz a obra de Roberto Acizelo, a constante presença, sob diferentes enfoques, do papel das letras, ou seja, da lingua e da literatura, na formação dos individuos, dos cidadãos, dos que tinham acesso aos diferentes niveis escolares, incluindo o aparecimento tardio, no Brasil, da área de Letras como profissão.

Esse aspecto, eu sublinho justamente para recuperar a importância, a dimensão dos estudos da lingua e da literatura para a formação do individuo e a forma como essa concepçāo se reflete no ensino, na constituição dos curriculos, na importância, maior ou menor, dada pela sociedade brasileira, ao longo da nossa história, a esses estudos especificos e à profissāo que geram. Isso porque, de uma certa maneira essas informações desfazem uma concepção corrente e atual de que os cursos de Letras sāo menos importantes que tantos outros para a sociedade, para a comunidade e para o conhecimento em geral.

Como segundo aspecto desse estudo a ser destacado para o interesse dessa nossa reflexāo, e como conseqüência da primeira afirmação, o autor vai expor e examinar curriculos de grandes colégios da época, como é o caso do Pedro II, no Rio de Janeiro, para demonstrar que esses colégios constituiam "verdadeiros centros universitários de letras". Para nós, além da informação em si, interessa saber que, no século XIX, os estudos literários ocupavam um lugar de maior relevo nas estruturas curriculares, nos PCNs da época, que os estudos de lingua que, sem ocupar um espaço especifico nesses currículos, estavam embutidos, por assim dizer, no ensino da retórica, da estilística, a serviço de uma concepção literária e ornamental da linguagem. Como explicita Roberto Acizelo, enfatizando o destaque para o ensino da literatura, "o sistema de ensino reflete [ia] o embate entre as duas vertentes dos estudos literários (...), a historicista e a retórico-poética" (Souza, 1999: 32), e nos oferece um quadro em que resume esse embate: 
Quadro n. 1

\begin{tabular}{|c|c|c|c|}
\hline Ano Serie & $5^{\circ}$ ano & $6^{\circ}$ ano & $7^{2}$ ano \\
\hline $1850-1857$ & & Retórlca & Retórica \\
\hline $1858-1859$ & & Retórica & Retórica e Poética \\
\hline $1860-1861$ & & Retórica e Poética & Retórica e Poética \\
\hline $1862 \cdot 1869$ & & Retórica & $\begin{array}{l}\text { Poética o Literatura } \\
\text { Nacional }\end{array}$ \\
\hline 1870.1876 & & Relórica e Poética & $\begin{array}{l}\text { História da Literalura } \\
\text { em geral e } \\
\text { especialmente da } \\
\text { portuguesa e da } \\
\text { nacional }\end{array}$ \\
\hline $1877-1878$ & Retórica e Poética & & Literalura \\
\hline $1879-1880$ & & $\begin{array}{l}\text { Retórica, Poética e Literatura } \\
\text { Nacional }\end{array}$ & $\begin{array}{l}\text { Português e Literatura } \\
\text { Geral }\end{array}$ \\
\hline $1881-1891$ & & $\begin{array}{l}\text { Retorica, Poética e Literatura } \\
\text { Nacional }\end{array}$ & $\begin{array}{l}\text { Portuguôs e História } \\
\text { Literária }\end{array}$ \\
\hline $1892-1894$ & & História da Literatura Nacional & \\
\hline 1895 & & Literatura Nacional & \\
\hline $1896-1897$ & & & $\begin{array}{l}\text { História da Literalura } \\
\text { Nacional }\end{array}$ \\
\hline 1898 & & & $\begin{array}{l}\text { História da Literatura } \\
\text { Geral e da Nacional }\end{array}$ \\
\hline $1899 / 1900$ & Literatura & Literatura & \\
\hline
\end{tabular}

Mas se essa era a situação do ensino naquele momento, refletindo concepções de lingua e de literatura harmonizadas com o pensamento filosófico e pedagógico da época, o panorama começa a se alterar a partir do final do século XIX, ocorrendo, como afirma o autor, "uma mudança de proporções na partilha do campo de letras entre os estudos de lingua e os de literatura, bem como a posiçāo hierárquica ocupada por tais estudos no conjunto dos curriculos" (...) "até 1878 lingua portuguesa preenche espaço bastante exiguo e restrito às séries iniciais; de 1879 a 1881, não obstante seu lugar continuar limitado, ela se coloca na série mais avançada, embora conjugando-se à história literária; enfim, a partir de 1882 amplia de modo substancial o seu território no conjunto do curriculo" (Souza, 1999: 98).

Com o quadro de número 4, o autor permite visualizar a posição da disciplina lingua portuguesa entre os anos de 1850 e 1905, portanto entre o final da metade do século passado e o começo do XX. 
BRAIT, Beth. Língua e literatura: uma falsa dicotomia.

Quadro n. 4

\begin{tabular}{|c|c|c|c|c|c|c|c|}
\hline Ano Série & $1^{\circ}$ ano & $2^{9}$ ano & $3^{9}$ ano & $4^{9}$ ano & $5^{\circ}$ ano & $6^{2}$ ano & $7^{\circ}$ ano \\
\hline $1850-1857$ & $\overline{G N}$ & & & & & & \\
\hline $1858-1861$ & $P$ & & & & & & \\
\hline $1862-1869$ & $\bar{P}$ & & & & & GF & \\
\hline $1870-1876$ & $P$ & & & & & & \\
\hline $1877-1878$ & $\bar{P}$ & $P$ & $P$ & & & & \\
\hline $1879-1880$ & & & & & & & $\overline{P L G}$ \\
\hline 1881 & $\mathbf{G}$ & & & & & & $\mathrm{PHL}$ \\
\hline $1882-1891$ & $\bar{P}$ & $\bar{P}$ & $\bar{P}$ & $\bar{P}$ & $\bar{P}$ & & PHL \\
\hline $1892-1894$ & $P$ & $P$ & $P$ & $P$ & $P$ & & \\
\hline 1895 & $\mathrm{P}$ & $\bar{P}$ & $P$ & & & & \\
\hline $1896-1898$ & $\bar{P}$ & $\bar{P}$ & $P$ & $P$ & $P$ & $\bar{P}$ & \\
\hline $1899-1905$ & $P$ & $P$ & $P$ & $P$ & & & \\
\hline
\end{tabular}

Legenda:

GN - Gramática nacional

GF - Gramática filosófica

G - Gramática

$P$ - Português

PLG - Português e literatura geral

PHL - Pontuguês e história literária

Naturalmente, essa mudança deve ser entendida a partir dos novos paradigmas que passam a vigorar nas ciências em geral e nas Ciências Humanas em particular. O ensino das Letras nāo poderia ficar imune ao cientificismo que vigora a partir da segunda metade do século XIX e começo do XX. A presença bastante forte da gramática, dos estudos da lingua portuguesa sintetizada no quadro 4 , anuncia, $\mathrm{e}$ Roberto Acizelo enfatiza em sua obra, a forte presença do ensino de linguas, a dominância desse ensino, que pode ser observada especialmente de 1912 e 1925. Essa tendência de estudos das línguas ou a disciplinas voltadas para o estudo da lingua tem a ver, como já assinalamos, com as mudanças na visāo a respeito desses estudos, e que foram introduzidas no Brasil desde a década de 70 do século XIX pelos estudos comparativos, por estudos caracterizados como "positivismo lingüistico", inaugurando-se como se sabe o periodo cientifico da filologia. 
Nas orientações que regem um dos programas destacados pelo autor, é possivel flagrar a visão de ensino e de lingua que, com base na orientaçāo cientificista do momento, propōe: a "lingua vernácula Ideve ser ensinada] sem se deter em discussões metaphysicas e polemicas, dando assim à grammatica o cunho de uma sciencia e nāo mais de uma arte" (Souza, 1999: 99), o que responde, por assim dizer, às propostas da poética e da retórica, formas de conhecimento da lingua mais voltadas para o bem falar, o bem se expressar. Mas a partir de 1926, a literatura retorna como disciplina autônoma.

Nessa perspectiva, poderiamos continuar e veriamos que os cursos de Letras vão moldando seus curriculos, pendendo mais para a lingua que para a literatura, ou vice-versa, introduzindo disciplinas voltadas para as teorias literárias e lingüisticas, refletindo, sempre e necessariamente, concepçōes mais gerais de linguagem, de estudos da linguagem, de direcionamentos cientificos e filosóficos.

Aqui paro com as reflexões sobre os curriculos, na medida em que acredito ter surpreendido caracteristicas que demonstram como a dicotomia lingua e literatura vai sendo tratada em função de concepções que têm muito a ver com perspectivas mais amplas, mais gerais, ligadas à filosofia, às ciências, aos paradigmas dominantes em cada momento.

E para situar o momento atual, em lugar de me apegar aos curriculos, que sāo diversificados, mas que contemplam lingua e literatura, escolhi situar o papel dos estudos da linguagem e sua interferência no trabalho com a lingua e com a literatura a partir da leitura, ainda que rápida, de diferentes textos. Antes de oferecer a vocês os textos e uma possivel leitura, gostaria apenas de lembrar que, nas Ciências Humanas em geral e na nossa área em particular, sempre que assumimos uma nova posição, que adotamos um novo paradigma, é impossivel deixar de lado ou pelo menos deixar de dialogar com o que veio antes. Brinco sempre, mas é verdade, que quando estamos falando de lingua, de literatura, de estudos lingüisticos e literários, achango que estamos inventando a pólvora ou descobrindo a fórmula da âgua, atguẹm lem-

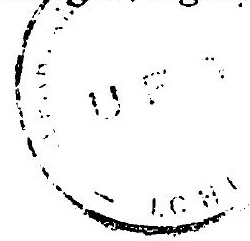


BRATT, Beth. Língua e literatura: uma falsa dicotomia.

bra como Aristóteles, por exemplo, já apontou para o mesmo aspecto de uma outra maneira. Quero dizer com isso que na nossa área não é possivel assumir uma determinada posição teórica ignorando a tradiçāo ou as tradiçōes dos estudos da linguagem que datam dos gregos e que não podem ser descartados.

Assim, se a retórica e a poética, que dominaram durante séculos os estudos ditos de Letras tiveram uma mudança com o apagamento da retórica durante um certo tempo, causado pelo trauma dos estudos que visavam "ao embelezamento da linguagem", "às fórmulas para o bem expressar-se", a partir dos anos 70, agora do século XX, novas formas de compreensão da linguagem vêm integrar literatura $e$ lingua, nāo pelo guarda-chuva dessa dicotomia, mas por uma idéia de linguagem que abriga não apenas o reconhecimento e a valorização da variaçāo lingüística, mas especialmente a sua abordagem a partir das categorias de texto, incluindo o verbal e o não verbal, o literário e o nāo literário, a norma culta e as demais normas, socorrendo-se de noçōes advindas dos estudos lingüísticos e literários, compreendidos entre as teorias poéticas, as teorias literárias, as teorias lingüisticas e as várias tendências da análise do texto e do discurso que, sem desprezar a materialidade lingũistica, muito ao contrário, centrando-se nos estudos sobre ela, acolhem o estudo da produçāo de sentidos a partir de uma noçāo mais ampla de texto e de discurso.

Assim, a velha retórica deixa de ser uma forma de estudar ou ensinar os enfeites dos discursos para reaparecer sob a forma da nova retórica em que os textos e os discursos são enfrentados como "não transparentes", "não neutros", mas como entidades mobilizadoras de estratégias de argumentação, de persuasão, de ambigūidade, mesmo nos lugares menos esperados. Dessa forma, aspectos que pareciam próprios dos estudos dos textos literários são surpreendidos em textos nāo literários, nāo para mostrar sua beleza, mas para mostrar que a produção de efeitos de sentido não é propriedade exclusiva dos discursos literários e poéticos, mas pode estar numa primeira página de jornal ou nos discursos que a midia veiculou sobre o Césio, em Goiânia, em que as metáforas da guerra e da doença transformam-se em pro- 
gramas de produção de sentido de tal forma que o que era uma qualidade negativa do material radioativo passa a ser, por contaminaçāo discursiva, uma propriedade de Goiânia e dos goianos, interferindo na vida dessa comunidade ${ }^{2}$. O que nāo é pouco e demonstra não apenas a capacidade e a atuação de determinados discursos e de suas formas de circulaçāo, mas também o campo aberto para os profissionais das Letras, não apenas como autoridades de sala de aula, mas como cidadãos cujo instrumental de trabalho possibilita uma interferência nas formas de produção, recepção e atuaçāo dos discursos sobre a sociedade.

O que se pode tirar dessa generalização é que a oposição binária lingua-literatura perde inteiramente seu significado quando olhamos essas duas criações humanas a partir de um conceito mais amplo de linguagem, envolvendo as particularidades da lingua e possibilidades de exploração e utilização dessas particularidades, considerando, repito, as formas de produção e circulação dos discursos numa dada comunidade e num dado momento, as particularidades das interaçōes, o poder de construçāo da linguagem e não apenas de representação, informação e expressão.

Assim, o profissional de Letras terá que conhecer muito bem a lingua, as suas variantes, a sua norma culta. Mas terá também de conhecer literatura, como uma das formas de expressar essa lingua e tudo que isso pode significar. Terá ainda de estar atento às teorias da linguagem em geral para ser capaz de enfrentar textos e fazer deles seu instrumento de ver e mostrar o mundo.

Para ser um pouco menos teórica, escolhi alguns textos para explicitar um pouco essa forma de enfrentamento da linguagem que estou propondo e que a meu ver auxilia o debate central desta $I V$ Semana de Letras: inicialmente, uma placa de trânsito fotografada por José Paulo Pais e que aparece na obra Um por todos (poesia reunida) [Brasiliense, 1986, poema de Meia palaura, 1973], que ajuda a entender a questão lingua/literatura, literário/não literário.

2 O estudo dessas metäforas è o tema da pesquisa de Regina Celeste Rocha de Barros, doutoranda da Área de Semiótica e Lingüistica Geral da FFLCH/USP. 


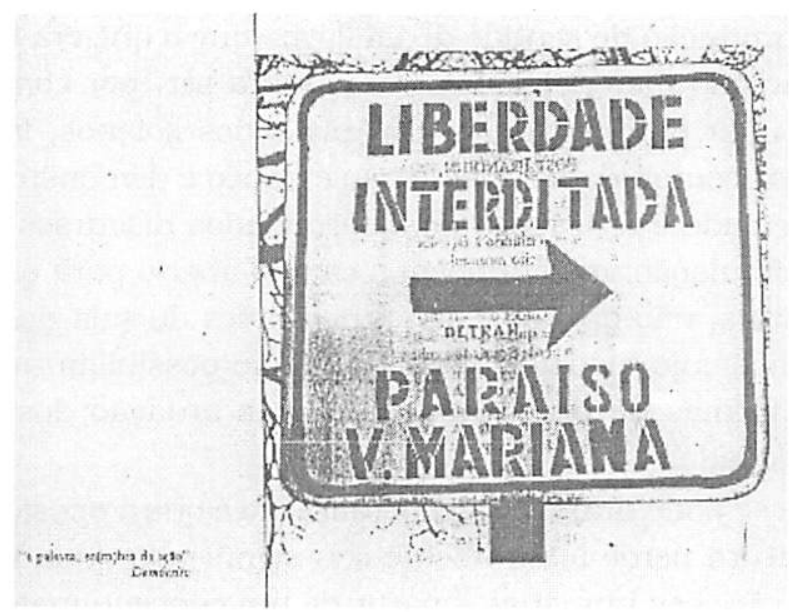

A placa de trânsito deve ser vista como um texto característico de um gênero, "o código de trânsito", que está relacionada a uma atividade humana específica, ou seja, a utilização de determinados espaços urbanos por pedestres ou motoristas.

Nesse sentido, é um texto objetivo, claro, sem ambigüidades ou efeitos de sentido inesperados. Também poderiamos dizer que a dimensão ideológica é praticamente zero.

A mesma placa, o mesmo texto, fotografado e colocado num livro de poemas, modifica-se inteiramente. Mudam as formas de produção, as formas de circulação e as formas de recepção. O mesmo texto passa a pertencer a um outro gênero, o poético, exigindo outros leitores, construindo outros sentidos, produzindo efeitos de sentido que a memória discursiva dos anos 70 pode motivar. Considere-se, por exemplo, a seqüência liberdade interditada. Na placa podia e era decodificada, por pedestres e motoristas, como Avenida Liberdade interditada ao trânsito em função de obras, um fato perfeitamente observável na década de 70, momento da construção do Metrô e da modificação dessa avenida paulistana. No livro de poemas, o referencial de trânsito funciona como suporte para uma dicção poética irônico-critica que constrói outros referentes a partir do interdiscurso ditatorial 
que vigia naqueles pesados anos. Se a placa hoje está totalmente decolada do real, uma vez que a Avenida da Liberdade não está mais interditada ao trânsito, o poema permanece como prova não apenas da perspicácia do fotógrafo, o grande poeta brasileiro José Paulo Pais, mas da permanência de uma memória discursiva, de uma realidade cruel, a partir não de um panfleto fabricado, mas de um artefato do dia-a-dia do cotidiano dos brasileiros.

A duplicidade da leitura da seta indicando à direita para chegar ao Paraíso fica como conseqüência das mudanças sofridas pelo deslocamento do texto e das memórias discursivas invocadas.

Para dar continuidade às leituras e ao jogo da linguagem, escolhi uma seqüência de uma primeira página de um jornal carioca.

Na quarta-feira dia 8 de setembro, o jornal O Globo apresentou como parte de sua primeira pagina a seguinte noticia:

\section{FH cobra unidade no Governo}

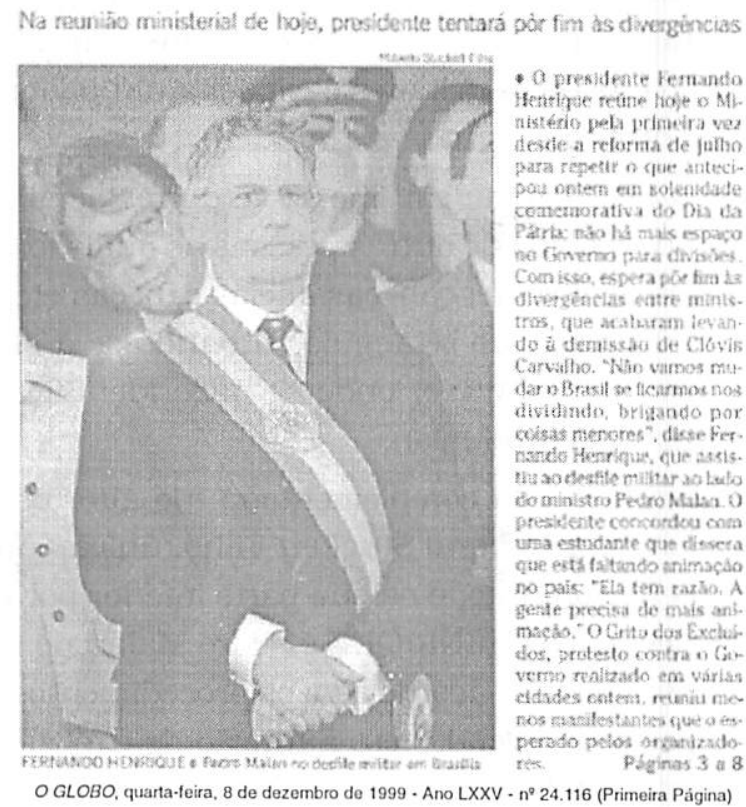


Para efeito de análise, vamos considerar:

a) que o gênero jornalistico noticia tem por objetivo primeiro informar e que a ambigüidade ou a produção de efeitos de sentido ambiguos, não precisos, deve estar fora dos propósitos e das formas de produção de um texto noticioso;

b) que a noticia é percebida pelo leitor como um todo e que, portanto, será considerada como um único texto, isto é, uma unidade verbo-visual produtora de sentido, formada por cinco componentes básicos, articulados, entre outros aspectos, pela diagramação, ou seja, pela forma simétrica como estão distribuidos, justapostos no retângulo;

c) que os componente que integram esse texto são:

- um titulo - FH cobra unidade no Governo, que ocupa a parte superior do retângulo e se destaca pelo tamanho e forma das letras;

- um subtitulo - Na reunião ministerial de hoje, presidente tentará por fim às divergências, que vem logo abaixo do título em letras menores e explicita um pouco mais o sentido do título;

- uma foto colorida em que se vê o presidente em primeiro plano, cercado de outras pessoas as quais foram flagradas apenas em parte: cabeças, meias cabeças etc. , que ocupa a maior parte do retângulo, situando-se à esquerda, logo abaixo do subtitulo, onde se pode identificar o rosto do ministro Pedro Malan;

- que a foto está complementada, no alto, por um crédito: foi feita por Roberto Stuckert Filho, única autoria identificada no conjunto; e na sua parte inferior por uma legenda - FERNANDO HENRIGUE e Pedro Malan no desfile militar em Brasilia - de acordo com os procedimentos jornalisticos de praxe, a legenda tem a função de explicitar o assunto da foto, vindo, necessariamente, logo abaixo dela; a expli- 
citação esclarece que a foto diz respeito ao dia anterior à data do jornal, ou seja, ao dia 7 de setembro e à presença do Presidente Fernando e do ministro Malan no desfile comemorativo à data;

- uma seqüência verbal que, diferentemente da legenda. nāo tem por função esclarecer o assunto da foto, o que poderia dar a impressão dada a justaposição foto/seqüência verbal, mas que vai detalhar as informaçōes sintetizadas no título e no subtitulo, ou seja, a unidade cobrada por Fernando Henrique diz respeito a um acontecimento que ainda está por vir, contemporâneo à data do jornal - 08/09/99 - e que consiste numa reunião ministerial, a primeira depois da reforma de julho e da demissão de Clóvis Carvalho, cujo objetivo seria, por parte do presidente, pôr fim às divergências existentes entre ministros, propor a unidade;

- Uma indicação de páginas que, colocada ao final do texto, remete o leitor ao detalhamento da seqüência verbal.

Considerando, portanto, os elementos básicos que compõem o conjunto, que constituem a noticia, o que se observa é que há dois acontecimentos, dois fatos de interesse público, que foram reunidos para compor o texto.

Por um lado, uma foto, um flagrante do momento em que o presidente e um dos ministros participavam do desfile militar do 7 de setembro em Brasilia, juntamente com outras autoridades. Por outro, uma informação sobre uma reunião ministerial que aconteceria no dia 8, com o detalhamento de seus objetivos.

Por que os dois acontecimentos estão reunidos formando um bloco coeso se, aparentemente, não pertencem ao mesmo momento, se dão em dias diferentes, e dizem respeito a diferentes atividades que envolveram e envolverāo o presidente da Repüblica? 
BRAIT, Beth. Lingua e literatura: uma falsa dicotomia.

De um ponto de vista jornalistico, a resposta é muito clara, muito objetiva, perfeitamente sustentável enquanto articulação de informaçōes: o presidente Fernando Henrique, no momento que participava das comemoraçōes do Dia da Pátria, antecipou aos jornalistas o motivo da reunião ministerial do dia seguinte, ou seja, "cobrar a unidade no governo".

Entretanto, a maneira como a notícia está diagramada, isto è, como o projeto gráfico reúne esta foto, e nāo outra, com os demais componentes do conjunto textual, possibilita ao leitor captar efeitos de sentido que vão além da explicaçāo real e jornalistica, porém simplista, da reunião dos dois acontecimentos. E é aqui que eu proponho que o profissional de Letras atue e, utilizando seus conhecimentos teóricos sobre linguagem, leitura, produção e recepção de textos, aponte, pelas relaçōes estabelecidas entre a materialidade lingüística e a materialidade visual, a reiteração, a ampliaçāo ou o redimensionamento de sentidos, mesmo em gêneros em que o esperado é a transparência textual, a utilizaçāo da linguagem como simples instrumento de informaçāo.

Comecemos pela coerente transparência e objetividade dessa noticia. Para que se possa considerar uma seqüência como um texto, é necessário que o conjunto forme uma unidade coerente e que se possa explicar essa coerência por alguns elementos que estabelecem a coesão entre as partes. Nesse caso especifico, é possivel dizer que estamos diante de um texto coerente, de uma noticia bem estruturada, levando em consideração os seguintes elementos que estabelecem a coesāo:

a) tanto no titulo, no subtitulo, quanto na foto e em sua legenda, como na seqüência verbal, o sujeito é o presidente Fernando Henrique, flagrado em atitudes públicas e governamentais e designado como "FH", "presidente", "FERNANDO HENRIQUE" e "O presidente Fernando Henrique";

b) as ações a ele atribuídas, em cada uma dessas seqüências, também funcionam como elementos de coesão, de articula- 
ção entre as partes, na medida em que, no título, por meio de um verbo no presente, ele "cobra a unidade"; no subtitulo, por meio de uma paráfrase que rediz essa ação no futuro, isto é, "tentará pôr fim às divergências", e na seqüência textual essa açāo é reiterada com a afirmaçāo "nāo há mais espaço no governo para divisões".

Portanto, a questão da unidade aparece como o núcleo central da noticia, da açāo do presidente junto aos ministros, num momento de mudança e crises ministeriais. Alguém poderia dizer que aqui há uma falácia, um engano de análise, na medida em que a foto e sua legenda não dizem respeito a essa unidade, a essa temática, não passando de um flagrante da participaçāo do presidente e do ministro no desfile militar de 7 de setembro. E é ai que nós entramos para dizer que o tema da unidade do governo está presente com força interpretativa, e até mesmo com um certo humor, na foto escolhida para compor a noticia.

Ao corpo de Fernando Henrique, flagrado não como simples cidadão brasileiro, mas como representante da naçāo, da Pátria que está sendo festejada nesse dia, o que se pode confirmar pela faixa presidencial que ele ostenta, destacada em suas cores e seu emblema, junta-se a cabeça do ministro Pedro Malan, formando um todo, ou seja, um único corpo com duas cabeças. Não se pode dizer que esta nāo seja uma versão de unidade, nāo exatamente a pretendida pelo presidente nos demais segmentos, mas a registrada, ainda que de maneira irreverente, casual, e um tanto monstruosa, pelas lentes do fotógrafo Roberto Stuckert Filho.

Portanto, a cobrança da unidade, a tentativa de pôr fim as divergências entre ministros e a ausência de espaço para divisöes no Governo, formas diferentes para dizer o mesmo propósito do Presidente, aparece como o tema central da noticia, configurando-se como informaçāo objetiva mas, ao mesmo tempo, abrindo pelo inusitado da foto, uma perspectiva critica, um efeito de sentido humorado que relativiza a realização desse objetivo. 
BRAIT, Beth. Lingua e literatura: uma falsa dicotomia.

Ainda aqui alguém poderia dizer que esse efeito de sentido está na cabeça obsessiva do analista de texto, do especialista em discurso, na medida que uma foto é sempre um flagrante da realidade e que, nesse caso, sendo uma foto jornalistica, com fins muito precisos e objetivos, assinada por um fotógrafo que pode ser responsabilizado pela imagem, a interpretação é gratuita. Seria apropriada se se tratasse de uma montagem.

De fato o efeito é de montagem e é isso que desestabiliza a interpretação referencial e única da foto. Mesmo num gênero que se quer objetivo como o jornalistico, quer na sua dimensāo textual ou visual, e especialmente nos gêneros especificos que se propōem a informar, como é o caso da noticia, e não de polemizar, despertar ou conduzir opiniōes, o projeto visual como um todo pode produzir efeitos de sentido que vão além da informação, muito além da simples informação, sugerindo interpretações.

Para comprovarmos que esse projeto visual, independente da intenção ou não do produtor ou dos produtores desse texto, de fato promoveu um efeito de sentido que extrapola a informação da simples participaçāo do presidente e do ministro no desfile militar, basta observar o mesmo jornal no dia seguinte ao da notícia. No dia 9 de setembro, portanto um dia depois da veiculaçāo dessa noticia, o mesmo jornal $O$ Globo publicou a seguinte charge: 


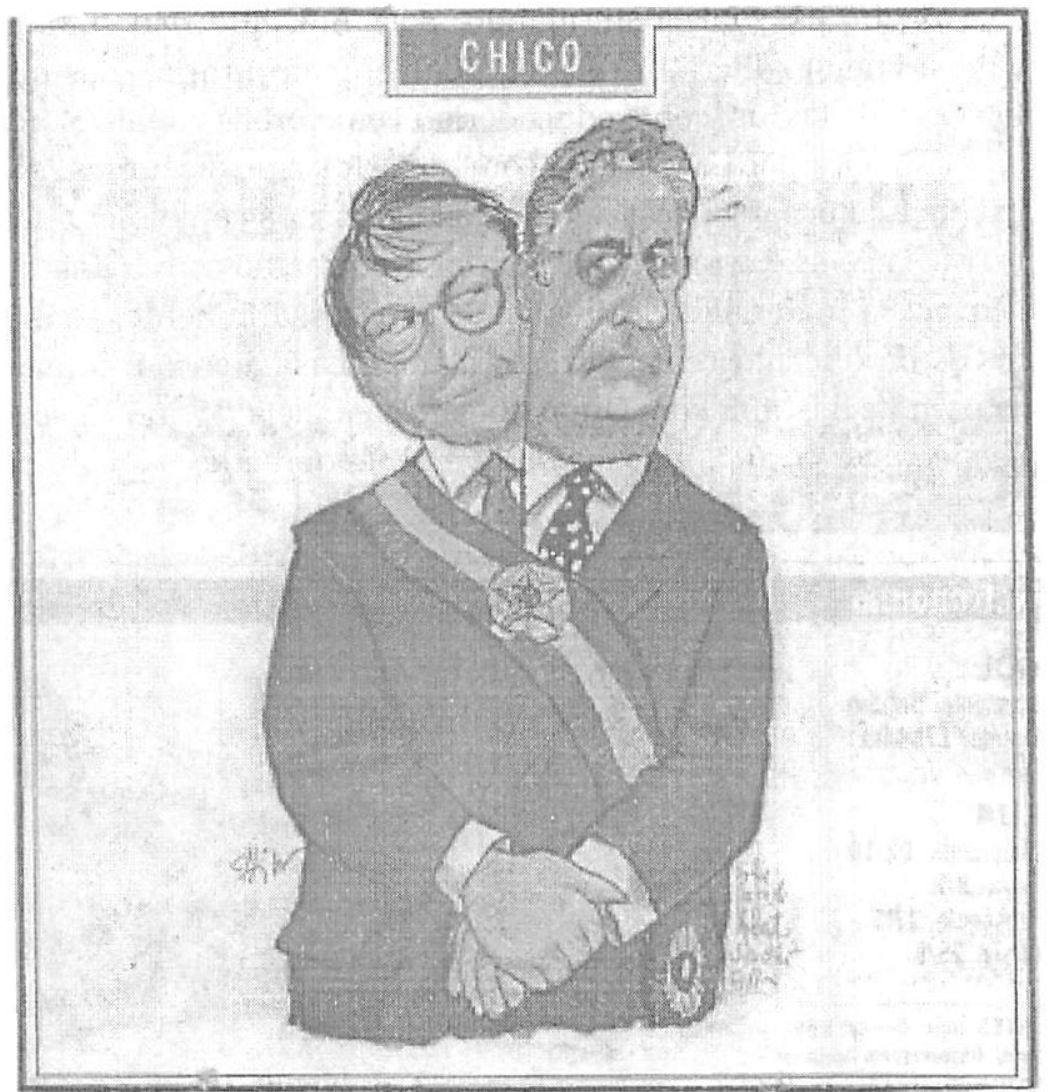

O GLOBO, quinta-feira, 9 de setembro de 1999 - Ano LXXV - n² 24. 117 (Primeira Página)

Nesse espaço jornalístico destinado ao gênero charge, cuja função é flagrar criticamente o cotidiano politico, o chargista recorta, da foto que compõe a noticia, justamente a unidade formada pelo corpo do presidente ao qual se junta a cabeça do ministro, agora também envolvido pela faixa presidencial, e na expressão de cada um, cujos olhares ganham direção diferente dos da foto, sinaliza o estranhamento dessa "monstruosa" composição. Aqui se confirma o efeito de sentido captado pelo chargista e apresentado por meio de sua charge. 
BRAIT, Beth. Língua e literatura: uma falsa dicotomia.

Concluo esta fala reafirmando, portanto, que não somente a dicotomia lingua - literatura é profundamente arbitrária, mas que ao profissional de Letras, como educador ou como profissional voltado de alguma maneira para o trabalho com os textos e os discursos, nāo se apresenta a alternativa dessa dicotomia, ao menos como mera divisão exclusiva, mas se lhe impōe o dever de um trabalho com a linguagem que envolve a materialidade lingüística e, necessariamente, suas condiçōes de produçāo, circulaçāo e recepção. E essa atenção, constante, é que permite assumir com Guimarães Rosa a idéia de que Mestre nāo é quem sempre ensina, mas quem de repente aprende. 